\title{
Avaliação do Resíduo da Construção e Demolição (RCD) em Solo-Cimento
}

\section{Bezerra, F. T. C.}

Escola Politécnica de Pernambuco Universidade de Pernambuco 50.720-001 - Recife, Brasil fernandatayane@hotmail.com

\author{
Lafayette, K. P. V. \\ Escola Politécnica de Pernambuco \\ Universidade de Pernambuco \\ 50.720-001 - Recife, Brasil \\ Autor2@meu-email
}

Resumo O crescente desenvolvimento das atividades de construção civil gerou uma preocupação dos profissionais com a grande quantidade de resíduos gerados pela mesma. Partindo deste princípio, esta pesquisa enfoca o solo-cimento, material proveniente da mistura de solo, cimento e RCD, o qual se procura obter os parâmetros geotécnicos e avaliar o comportamento mecânico de seus componentes isolados e posteriormente suas misturas em diferentes percentuais de composição. Na metodologia foram coletados materiais oriundos da construção civil, executados ensaios de caracterização física do solo e do RCD e fabricados blocos cilíndricos com diferentes traços e teores de cimento que foram submetidos a ensaios de compressão simples. Os resultados mostraram que o solo-cimento apresenta os parâmetros de resistência exigidos pela norma, revelando uma alternativa economicamente sustentável. Com o emprego desta alternativa haverá uma diminuição no consumo dos recursos naturais, destinação adequada aos resíduos, incentivo a investimentos na fabricação de materiais reciclados e diminuição nos custos.

Palavras-Chave: Resíduos da Construção e Demolição. Solo-Cimento.

\begin{abstract}
The growing development of construction activities generated a concern of professionals with the large amount of waste generated by herself. With this assumption, this research focuses on soil-cement, material from the mixture of soil, cement and RCD, which is seeking geotechnical parameters and evaluate the mechanical behavior of its individual componentes and subsequently their mixtures in diferente percentages of composition. In the methodology were collected materials from the construction, characterization tests performed soil physical and RCD and manufactured cylindrical blocks with diferente features and levels of cement were tested for compressive. The results showed that the soil-cement has the strength parameters required by the standard, revealing an economically sustainable. With the use of this alternative will be a decrease in consumption of natural resources, proper disposal of waste, encouraging investments in the manufacturing of recycled materials and reducing costs.
\end{abstract}

Keywords: Construction and Demolition Residues. Soil-Cements. 


\section{Introdução}

É notável o crescimento das pequenas e grandes cidades no Brasil e no mundo, segundo os números do censo 2010, a população das cidades dobrou nos últimos dez anos, passou de 3.054 pessoas em 2000 para $6.377 \mathrm{em}$ 2010. Um crescimento médio de mais de $10 \%$ ao ano. Com isso também é perceptível o número significativo de pessoas que migram para os centros urbanos, geradores de emprego e renda, que vivem um processo de crescimento desordenado. O aumento da população e o desenvolvimento econômico é um dos fatores que provocam o aumento no número de construções de grande porte, acarretando aumento na geração de resíduos pela construção civil. Nesses termos, tornam-se necessário a adoção de medidas que possam minimizar a deposição desse tipo de resíduo em aterros sanitários garantindo assim uma solução economicamente sustentável.

Sabendo da crescente necessidade de novas moradias, os tijolos de solo-cimento apresentam uma alternativa interessante para construção de casas populares já que podem ser feitos no próprio canteiro de obras, diminuindo o custo orçamentário sem comprometer a durabilidade dos imóveis.

Este artigo tem por objetivo viabilizar o uso do resíduo da construção e demolição em misturas de solocimento, criando materiais alternativos que atendam os padrões de qualidade técnica com consequente diminuição dos custos.

\section{Solo-Cimento}

Segundo a ABCP (1999) [2], o solo-cimento é o produto resultante da mistura íntima de solo, cimento portland e água que, compactados na umidade ótima e sob a máxima massa específica seca, em proporções previamente estabelecidas, adquire resistência e durabilidade através das reações de hidratação do cimento. Os principais fatores que afetam a propriedades do solo-cimento são: tipo de solo, teor do cimento, teor de umidade, compactação e homogeneidade da mistura, além da idade e do processo de cura.

A conceituação do solo-cimento teve origem em Sallsburg no ano de 1917, entretanto, havia poucos relatos até 1932, quando se teve notícia dos primeiros trabalhos cientificamente controlados, como por exemplo, a pavimentação de $17.000 \mathrm{~m}^{2}$ em Johnsonville, Carolina do Sul, EUA (ANDRADE FILHO, 1989) [3]. O interesse pelo assunto no Brasil se deu a partir de 1936, através da ABCP - Associação Brasileira de Cimento Portland, que regulamentou e pesquisou sua aplicação. Segundo Ferraz (2004) [4], o emprego deste material em edificações foi iniciado no
Brasil em 1948, com a construção das casas do Vale Florido, na Fazenda Inglesa, em Petrópolis - RJ. Desde então, a experiência brasileira vem sendo bastante ampliada, com aplicação de novas técnicas construtivas, avanços na tecnologia dos materiais e aprimoramento dos equipamentos de produção.

Segantini (2000) [5] afirma que, quanto a granulometria, os solos arenosos são mais apropriados para a confecção do solo-cimento. A existência de grãos de areia grossa e de pedregulhos é altamente benéfica, pois são materiais inertes com função apenas de enchimento. Isso favorece a liberação de quantidades maiores de cimento para aglomerar os grãos menores. Os solos devem também ter um teor mínimo da fração fina, pois a resistência inicial do solocimento é devida à coesão da fração fina compactada.

De acordo com ABCP (1999) [2], a dosagem do solocimento deve ser feita por meio de ensaios de laboratório, passando pela análise e interpretação dos resultados com base em critérios pré-estabelecidos. O resultado final consiste na fixação de três parâmetros: quantidade de cimento, quantidade de água e massa específica aparente seca máxima. Os dois últimos sofrem pequenas oscilações em função das variações que ocorrem nas características do solo. Assim, o objetivo da dosagem passou a ser somente a fixação da quantidade adequada de cimento, de acordo com tabela 1 .

Tabela 1. Teores de Cimento (ABNT, 1999).

\begin{tabular}{|c|c|}
\hline Classificação HRB & Teor de Cimento (\%) \\
\hline A1a & 5 \\
\hline A1b & 6 \\
\hline A2 & 7 \\
\hline A3 & 8 \\
\hline A4 & 10 \\
\hline A5 & 10 \\
\hline A6 & 12 \\
\hline A7 & 13 \\
\hline
\end{tabular}

\section{Introdução}

\subsection{Estilos}

Neste trabalho foram utilizados os seguintes materiais:

\subsubsection{Estilos}

O Solo utilizado neste trabalho foi coletado próximo ao Porto de SUAPE em Pernambuco. Trata-se de um solo 
A6, segundo a classificação HRB - Higway Research Board,.

\subsubsection{Resíduo do Concreto}

Os resíduos de concreto foram coletados em caçambas coletoras de entulhos existentes em canteiros de obras em Recife-PE, primeiramente fez-se a composição gravimétrica e, em seguida, todo o material foi processado em triturador de mandíbulas e passado na peneira de malha $4.8 \mathrm{~mm}$, visando a sua transformação em material granular (Figura 1).

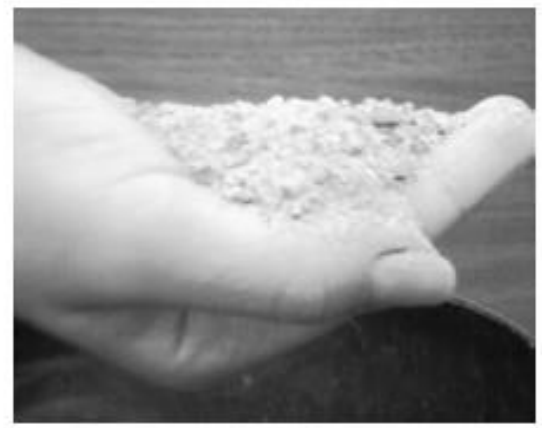

Fig. 1. Residuo de concreto após o processo de britagem

\subsubsection{Cimento}

Foi utilizado o cimento CP II Z 32, da marca Nassau, já que é um cimento composto, com adições normalizadas, para uso e aplicação geral, em que não há necessidade de resistência elevada nas primeiras idades.

\subsection{4 Água}

Utilizou-se a água potável proveniente da rede pública de abastecimento.

\section{Métodos}

No primeiro momento, foram realizados ensaios de caracterização das amostras de solo, de RCD e das misturas destes, que englobam os ensaios de granulometria (por peneiramento e por sedimentação), densidade real dos grãos, análise mineralógica e ensaio de compactação com energia Proctor. Estes ensaios foram realizados em conformidade com as normas brasileiras pertinentes.

Na composição do solo-cimento, foram estudadas dosagens compostas por solo natural, solo $+25 \%$ de RCD, solo $+50 \%$ de $\mathrm{RCD}$, solo $+75 \%$ de $\mathrm{RCD}$ em relação à massa de solo. Para cada uma dessas composições, o teor de cimento utilizado foi de $8 \%$ em relação à massa da mistura solo-resíduo. Foram moldados dois corpos-de-prova cilíndricos referentes a cada traço estudado (solo $+8 \%$ de cimento, solo $+8 \%$ de cimento $+25 \%$ de $\mathrm{RCD}$, solo $+8 \%$ de cimento $+50 \%$ de RCD e solo $+75 \%$ de RCD). A confecção desses corpos-de-prova cilíndricos serviu para avaliar o comportamento da resistência à compressão simples do solo-cimento ao longo do tempo e para determinar o valor de absorção d'água. Depois de moldados, os corposde-prova foram transferidos para câmara úmida do Laboratório de Materiais de Construção da UPE (Figura 2).

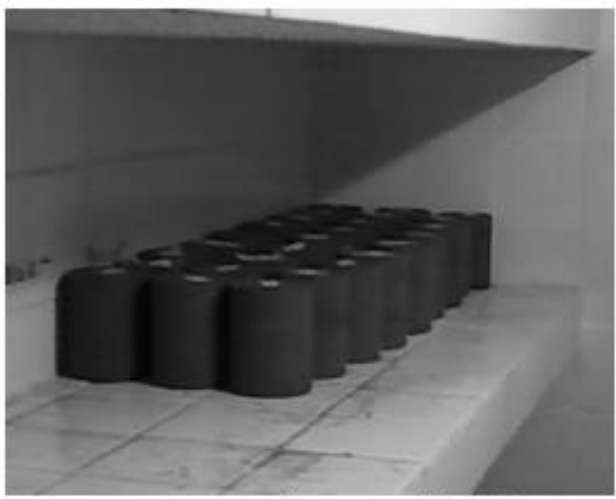

Fig.2. Corpos-de-prova cilindricos na câmara úmida.

Os ensaios foram realizados em conformidade com as Normas Brasileiras pertinentes, a seguir descritas:

- NBR 6457 (1986) Amostras de Solo - Preparação para ensaios de compactação e ensaios de caracterização; [10]

- NBR 6459 (1984) Solo - Determinação do Limite de Liquidez; [11]

- NBR 7180 (1984) Solo - Determinação do Limite de Plasticidade; [12]

- NBR 6508 (1984) Solo - Grãos de solo que passam na peneira de $4,8 \mathrm{~mm}$ - Determinação da massa especifica; [13]

- NBR 7181 (1984) Solo - Análise granulométrica; [14]

- NBR 7182 (1986) Solo - Ensaio de compactação; [15]

- NBR 12024 (1992) Solo-Cimento: Moldagem e cura dos corpos-de-prova cilíndricos; [16]

- NBR 12025 (1990) Solo-Cimento: Ensaio de 
compressão simples de corpos-de-prova cilíndricos; [17]

- NBR 13555 (1996) Solo-Cimento: Determinação da absorção de água. [18]

\section{Resultados e discussões}

\subsection{Composição Gravimétrica do RCD}

A Figura 3 apresenta o percentual de cada material presente na amostra de RCD na fase de estrutura de acordo com a separação tátil-visual realizada.

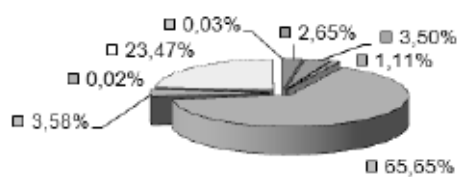

\begin{tabular}{|c|c|c|}
\hline 口MIÚDO & 口TIJOLOS CERÅMICOS & 口ARGAMASSA \\
\hline ICONCRETO & 口CONCRETO ARMADO & 口SOLO \\
\hline 口MISTO & DOUTROS & \\
\hline
\end{tabular}

Fig. 3. Composição Gravimétrica do RCD.

\subsection{Composição Granulométrica}

Na Tabela 2 apresentam-se os resultados obtidos nos ensaios de análise granulométrica

Tabela 2. Composição granulométrica das amostras.

\begin{tabular}{|c|c|c|c|c|}
\hline Amostra & $\begin{array}{c}\text { Argila } \\
(\%)\end{array}$ & $\begin{array}{r}\text { Silte } \\
(\%)\end{array}$ & $\begin{array}{c}\text { Areia } \\
(\%)\end{array}$ & $\begin{array}{c}\text { Pedr. } \\
(\%)\end{array}$ \\
\hline Solo & 44,05 & 18,03 & 37,92 & 0,0 \\
\hline RCD & 3,58 & 10,42 & 84,75 & 1,25 \\
\hline $\begin{array}{c}\text { Solo }+ \\
25 \% \text { RCD }\end{array}$ & 5,78 & 3,28 & 90,72 & 0,22 \\
\hline $\begin{array}{c}\text { Solo }+ \\
50 \% \text { RCD }\end{array}$ & 2,72 & 3,72 & 92,34 & 1,22 \\
\hline $\begin{array}{c}\text { Solo }+ \\
75 \% \text { RCD }\end{array}$ & 8,51 & 7,91 & 82,47 & 1,11 \\
\hline
\end{tabular}

Pode-se observar que as misturas das amostras de RCD estudada são formadas, essencialmente, por materiais granulares (arenosos), tendo-se em menor quantidade o silte e a argila.

\subsection{Análise Mineralógica}

Para análise dos constituintes mineralógicos da amostra de RCD e de Solo com grãos de diâmetros pré-definidos, separou-se uma pequena quantidade do material e com auxilio de uma Lupa Leica EZ4D foi possível visualizar os minerais constituintes da amostra. Observou-se que na fração de RCD (Figura4) há predominância de quartzoso e de grãos angulosos a muito angulosos.

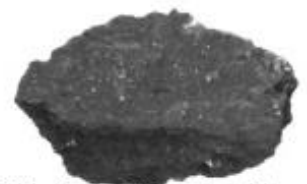

Fig 4-a. Grâo de Alvenaria.

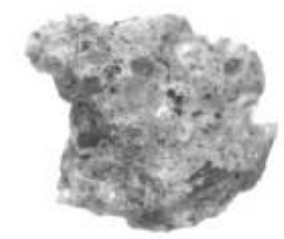

Fig 4-b. Grão de Cimento.

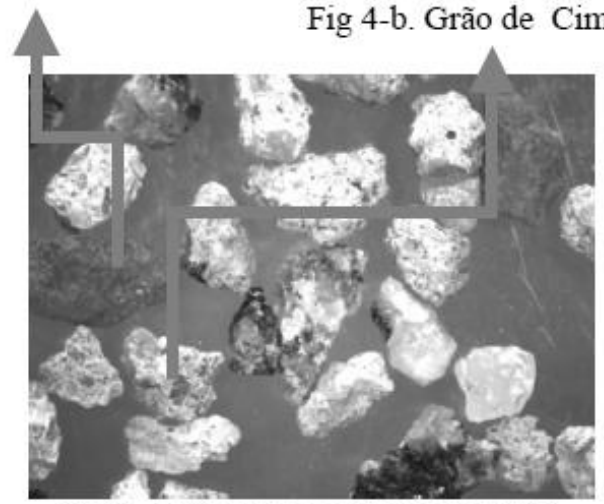

Fig 4. Análise mineralógica do RCD.

\subsection{Resistência à compressão dos corpos-de- prova cilindros}

Os corpos-de-prova foram retirados da câmara úmida após o período de 60, 90 e 120 dias de cura e foram encaminhados para imersos em água durante 4 horas. E em seguida rompidos por compressão simples no laboratório Avançado de Construção Civil da escola Politécnica de Pernambuco

Apresentam-se na Tabela 3 os resultados obtidos no ensaio de compressão simples. 
Tabela 3. Resistência à compressão simples.

\begin{tabular}{|c|c|c|c|}
\hline \multirow{2}{*}{ Traço } & \multicolumn{3}{|c|}{ Resistência Média (MPa) } \\
\cline { 2 - 4 } & $\begin{array}{c}60 \\
\text { dias }\end{array}$ & 90 dias & $\begin{array}{c}120 \\
\text { dias }\end{array}$ \\
\hline $\begin{array}{c}\text { Solo + 8\% de } \\
\text { cimento }\end{array}$ & 2,34 & 2,48 & 2,55 \\
\hline $\begin{array}{c}\text { Solo + 8\% de } \\
\text { cimento }+25 \% \\
\text { de RCD }\end{array}$ & 4,02 & 6,36 & 6,93 \\
\hline $\begin{array}{c}\text { Solo + 8\% de } \\
\text { cimento }+50 \% \\
\text { de RCD }\end{array}$ & 7,94 & 9,58 & 13,96 \\
\hline $\begin{array}{c}\text { Solo }+8 \% \text { de } \\
\text { cimento }+75 \% \\
\text { de RCD }\end{array}$ & 8,07 & 14,23 & 18,32 \\
\hline
\end{tabular}

\section{Conclusões}

Pela análise dos resultados, pode-se concluir que:

O Resíduo da Construção e Demolição, especificamente o de concreto, revelou-se uma alternativa para a fabricação de tijolos de solo-cimento, uma vez que ao melhorar as propriedades mecânicas do solo garante maior resistência ao produto. Além disso, sua adição minimizará a quantidade de resíduos destinados aos aterros e conseqüentemente a extração de matéria - prima para este fim. Os ensaios físicos constataram que os RCD's apresentam características granulométricas equivalentes a areias bem graduadas.

Por meio da analise mineralógica dos grãos observouse que a fração de RCD na amostra de alvenaria tem a predominância de grãos de sub-angulosos a anguloso, a uma grande presença de quartzo revestido com material cimentício e óxido de ferro, com a presença da biotita e muscovita, pode-se concluir que o grau de intemperização do material é baixo.

Quanto às propriedades tecnológicas, verificou-se que as misturas nas proporções de $25 \%, 50 \%$ e $75 \%$ atenderam às especificações para o emprego como solo-cimento. Todos os corpos-de-prova mostraram que a quantidade de cimento adicionada ( $8 \%$ em massa), permitiu que a mistura solo-cimento atingisse uma resistência superior a indicada pela norma que é de 2,1 MPA.

Diante da análise dos dados, observou-se que o emprego de Resíduo da Construção e Demolição pode ser considerado como um novo material que vai diminuir drasticamente a quantidade de entulho lançados no meio ambiente, gerando novas oportunidades nas indústrias de beneficiamento e reduzindo custos nas obras.

\section{Conclusões}

A realização dessa pesquisa só foi possível devido a enorme ajuda do laboratorista do Laboratório de Mecânica dos Solos da Escola Politécnica de Pernambuco, Fábio Ferreira, que esteve presente na execução de todos os ensaios. Agradeço a Prof Kalinny Lafayette por todos os seus atos como orientadora e amiga.

\section{Referências}

[1] JOHN, V. M. Reciclagem de resíduos na construção civil: contribuição à metodologia de pesquisa e desenvolvimento. 2000. $102 \mathrm{f}$. Tese (Livre Docência) - Escola Politécnica, Universidade de São Paulo, São Paulo, 2000.

ASSOCIAÇÃO BRASILEIRA DE CIMENTO PORTLAND - ABCP. Dosagem das misturas de solocimento: normas de dosagem e métodos de ensaio. São Paulo-SP, 1999. ABCP, ET-35, 51p.

[3] ANDRADE FILHO, J. Reforço de solos com a utilização de tubulões em solo-cimento. Dissertação (Mestrado) - Escola de Engenharia de São Carlos. São Carlos, 1989, 190p.

[4] SEGANTINI, A. A. S. Utilização de solo-imento plástico em estacas escavadas com trado mecânico em Ilha Solteira (SP). 2000. 176 f. Tese (Doutorado) - Faculdade de Engenharia Civil, Universidade Estadual de Campinas, Campinas, 2000.

[5] SOUZA, M. I. B. Análise da adição de resíduos de concreto em tijolos prensados de solo-imento. 2006. 116 f. Dissertação (Mestrado) - Faculdade de Engenharia, Universidade Estadual Paulista “Júlio de Mesquita Filho”,Ilha Solteira, 2006.

[6] ASSOCIAÇÃO BRASILEIRA DE NORMAS TÉCNICAS. NBR 6457: Amostra de solo - preparação para ensaios de compactação e ensaios de caracterização. Rio de Janeiro, 1986. 9 p.

[7] ASSOCIAÇÃO BRASILEIRA DE NORMAS TÉCNICAS. NBR 6459: Solo- Determinação do limite de liquidez. Rio de Janeiro, 1984. 6 p.

[8] ASSOCIAÇÃO BRASILEIRA DE NORMASTÉCNICAS. NBR 7180: Solo - Determinação do limite deplasticidade. Rio de Janeiro, 1984. 3 p. 
[9] ASSOCIAÇÃO BRASILEIRA DE NORMAS TÉCNICAS. NBR 6508: Grãos de solo que passam na peneira de $4,8 \mathrm{~mm}$ - Determinação da massa específica. Rio de Janeiro, 1984. 7 p.

[10] ASSOCIAÇÃO BRASILEIRA DE NORMAS TÉCNICAS. NBR 7181: Solo - Análise granulométrica. Rio de Janeiro, 1984. 13 p.

[11] ASSOCIAÇÃO BRASILEIRA DE NORMAS TÉCNICAS. NBR 7182: Solo-Ensaio de compactação. Rio de Janeiro, 1986. 10 p.

[12] ASSOCIAÇÃO BRASILEIRA DE NORMAS TÉCNICAS. NBR 12024: Solo---cimento-Moldagem e cura dos corpos---de---prova cilíndricos. Rio de Janeiro 1990. 5 p.

[13] ASSOCIAÇÃO BRASILEIRA DE NORMAS TÉCNICAS. NBR 12025: Solo---cimento-Ensaio de compres são simples de corpos---de---prova cilíndricos. Rio De Janeiro, 1990. 2 p.

[14] ASSOCIAÇÃO BRASILEIRA DE NORMAS TÉCNICAS. NBR 13555: Solo---cimento-Determinação da absorção d'água. Rio de Janeiro, 1996. 2 p.

[15] ABNT---Associação Brasileira de Normas técnicas. NBR15115: Agregados reciclados de resíduos sólidos da construção civil--execução de cama das de pavimentação-Procedimentos. 10p Rio de Janeiro, 2004 